\title{
PROSPECTS FOR THE DEVELOPMENT OF THE ESCROW AGREEMENT IN RUSSIA
}

\author{
Natalia V. Kvitsinia \\ Volgograd State University, Volgograd, Russian Federation
}

\begin{abstract}
Introduction: the paper deals with such issues as the content and objectives of the escrow agreement, its special aspects and distinctive features in relation to other forms of payments, and the development of the escrow agreement in foreign countries and the Russian Federation. Purpose: using the methods of scientific knowledge - logical, dialectical, and comparative law - in order to identify the areas of improvement of the escrow agreement in the field of regulation of the rights and obligations of the depositor, beneficiary and escrow-agent the role of the escrow agreement in the implementation and protection of the rights of the parties to the agreement was analyzed by the author. Results: the consolidation of the escrow agreement as an institution of the civil legislation of the Russian Federation made it possible to protect the interests of the contractors, reduce the risks and protect the parties from possible fraudulent actions and most fully ensure the fulfillment of contractual obligations primarily on the part of the beneficiary. Conclusions: the escrow agreement in civil law is a new institution that requires improvement and adaptation; this will be one of the most effective mechanisms for protecting the rights of business participants in the construction sector. The development of the legal regulation of the escrow agreement, including the development of the escrow account agreement, will particularly help to guarantee the protection of the customers' rights in the shared construction contract.

Key words: escrow agreement, escrow account agreement, escrow, settlements, beneficiary, depositor.

Citation. Kvitsinia N.V. Prospects for the Development of the Escrow Agreement in Russia. Legal Concept, 2020, vol. 19, no. 1, pp. 51-59. (in Russian). DOI: https://doi.org/10.15688/lc.jvolsu.2020.1.6

\section{ПЕРСПЕКТИВЫ РАЗВИТИЯ ДОГОВОРА ЭСКРОУ В РОССИИ}

\section{Наталья Вячеславовна Квициния}

Волгоградский государственный университет, г. Волгоград, Российская Федерация

Введение: в статье рассматриваются такие вопросы, как содержание и цели договора эскроу, его особенности и отличительные черты по отношению к другим формам расчетов, развитие договора условного депонирования в зарубежных странах и Российской Федерации. Цель: с помощью методов научного познания, а также логического, диалектического, сравнительно-правового методов автором в целях выявления направлений совершенствования договора эскроу в области регулирования прав и обязанностей депонента, бенефициара и эскроу-агента была проанализирована роль договора эскроу в реализации и защите прав участников соглашения. Результаты: закрепление договора эскроу как института гражданского законодательства Российской Федерации дало возможность защитить интересы контрагентов, снизить риски и обезопасить стороны от возможных мошеннических действий и наиболее полно обеспечить исполнение договорных обязательств в первую очередь со стороны бенефициара. Выводы: договор эскроу в гражданском праве является новым институтом, требующим совершенствования и доработки, что будет являться одним из наиболее эффективных механизмов защиты прав участников предпринимательской деятельности в строительной сфере. Развитие правового регулирования договора эскроу, в том числе развитие договора счета эскроу, поможет гарантировать защиту прав заказчиков в договоре долевого строительства.

Ключевые слова: договор эскроу, договор счета эскроу, условное депонирование, расчеты, бенефициар, депонент. 
Цитирование. Квициния Н. В. Перспективы развития договора эскроу в Pоссии // Legal Concept $=$ Правовая парадигма. - 2020. - Т. 19, № 1. - C. 51-59. - DOI: https://doi.org/10.15688/lc.jvolsu.2020.1.6

\section{Введение}

Одной из самых актуальных проблем в рамках гражданского оборота всегда была и остается проблема доверия сторон договора друг другу. Поэтому задачей гражданского законодательства является решение таких серьезных вопросов, как обеспечение безопасности денежных средств, предотвращение мошенничества со стороны недобросовестного контрагента и наиболее полное обеспечение исполнения договорных обязательств обеими сторонами. Для разрешения подобных проблем в гражданском законодательстве было закреплено немало юридических механизмов, способных в той или иной мере защитить интересы контрагентов, снизить риски и обезопасить стороны от возможных недобросовестных действий.

Договор эскроу, или договор условного депонирования, равно как договор счета эскроу, является, на наш взгляд, одним из наиболее оптимальных и современных юридических конструкций, обеспечивающих одновременное исполнение договорных обязательств обеими сторонами.

Идея создать такой гражданско-правовой договор возникла при обсуждении реформы гражданского законодательства. В это время и было принято решение о разработке данной конструкции и включении ее во вторую часть Гражданского кодекса Российской Федерации в качестве новой главы (гл. 47.1), которая получила название «Условное депонирование (эскроу)». При этом следует отметить, что впоследствии данная конструкция была признана законодателем очень эффективной, в связи с чем разновидность этого договора была введена в отечественное гражданское законодательство о банковском счете в форме договора счета эскроу (§ 3 главы 45 ГК РФ).

Такой договор предусматривает открытие банком (эскроу-агентом) специального счета для учета и блокирования денежных средств, полученных от владельца счета (де- понента), в целях передачи другому лицу (бенефициару) при возникновении предусмотренных договором оснований (ст. 860.7 ГК РФ). Данный договор используется чаще всего при исполнении договора долевого участия в строительстве, в первую очередь потому, что договор счета эскроу был изначально внедрен в гражданское законодательство именно с целью защиты прав участников долевого строительства.

Отношения между гражданами и организациями, которые осуществляют строительство, регулируются Федеральным законом от 30 декабря 2004 г. № 214 «Об участии в долевом строительстве многоквартирных домов и иных объектов недвижимости и о внесении изменений в некоторые законодательные акты Российской Федерации». Предметом регулирования являются отношения, которые связаны с привлечением денежных средств граждан и юридических лиц для долевого строительства, для возмещения затрат на такое строительство, и с возникновением у участников долевого строительства права собственности на объекты. Закон также устанавливает гарантии защиты прав, законных интересов и имущества этих участников [6].

Количество обманутых дольщиков увеличивается с каждым годом. По данным Министерства строительства Российской Федерации, на сентябрь 2018 г. зафиксировано более 34 тысяч «обманутых дольщиков» [4]. В связи с этим 1 июля 2018 г. в Федеральный закон № 214 были внесены изменения, которые предусматривают постепенный переход к проектному финансированию с участием счета эскроу.

По данным национального проекта «Жилье и городская среда», число договоров долевого участия в строительстве превысит один миллион к концу 2024 года. По данным вице-премьера В. Мутко, в марте 2019 г. несколькими крупнейшими банками было заключено 55 договоров на получение проектного кредитования и открыто около 1300 эскроу-счетов [5]. 


\section{Понятие договора эскроу, его содержание и цели}

Договор эскроу - это договор, по которому одна сторона (депонент) обязуется передать определенное имущество эскроу-агенту, который, в свою очередь, обязуется обеспечить сохранность имущества и передать его другой стороне (бенефициару) при условии исполнения им договорных обязательств. В качестве сторон договора счета эскроу, как правило, выступают физические и юридические лица. Депонентом является должник по договору, бенефициаром - исполнитель, или кредитор. Функцию эскроу-агента (или агента счета) выполняет обычно кредитная организация.

На практике нередко встречаются случаи, когда стороны договора несут взаимные обязательства. Согласно п. 6 ст. 926.1 ГК РФ, физические или юридические лица могут заключить договор эскроу, по которому каждая из сторон депонирует эскроу-агенту имущество для дальнейшей его передачи в случае соблюдения ими условий договора. Здесь каждая из сторон договора одновременно выполняет функцию как депонента (так как имеет определенное обязательство по передаче имущества эскроу-агенту), так и бенефициара (обладает правом требования к эскроу-агенту по передаче имущества).

Рассмотрим содержание договора счета эскроу:

1) депонент обязан передать безналичные денежные средства, наличные денежные средства, ценные бумаги или иное имущество эскроу-агенту и вправе требовать исполнения обязательств по договору от бенефициара, который вместе с тем является кредитором по другому договору, заключенному с эскроуагентом;

2) бенефициар обязан выполнить договорные условия перед депонентом, а также имеет право требовать от эскроу-агента передачи депонируемого имущества при соблюдении им договорных условий;

3) эскроу-агент обязан надлежащим образом хранить депонируемое имущество, несет ответственность за утрату, повреждение данного имущества в случае, если не сможет доказать, что несохранность вещей была вызвана вследствие непреодолимой силы, свой- ствами депонируемого имущества, либо же в результате умысла или неосторожности депонента. Однако эскроу-агент вправе требовать, как от депонента, так и от бенефициаpa, уплаты определенного вознаграждения за исполнение им договорных обязательств. Обычно обязательства депонента и бенефициара по отношению к эскроу-агенту солидарны (если иное не предусмотрено договором), но здесь существует одно правило: эскроу-агент не имеет права удерживать часть депонируемого имущества в счет оплаты своего вознаграждения.

В случае, если депонент передает эскроу-агенту вещи (причем не только индивидуально определенные, но и определенные родовыми признаками), депонент сохраняет право собственности на них, однако после передачи данного имущества на депонирование депонент не имеет права распоряжаться данным имуществом в течение всего срока действия договора.

Если депонент передает на депонирование эскроу-агенту безналичные денежные средства или бездокументарные ценные бумаги, то эскроу-агент хранит их на обособленных счетах (лицевых, расчетных и др.) и может использовать данные средства только для исполнения им обязательств по договору эскроу, хотя распоряжаться данным имуществом не имеет права. Существует определенная особенность депонирования безналичных денежных средств в тех случаях, когда в качестве эскроу-агента выступает лицо, не являющееся кредитной организаций (например, юридическая компания): данные средства хранятся на лицевом счете эскроу-агента, но бенефициаром по договору банковского счета является депонент до того момента, пока не возникнут основания передачи данного имущества бенефициару по договору эскроу. После этой даты бенефициаром становится бенефициар по договору эскроу.

Выделим основные цели договора эскроу: обеспечение исполнения договорных обязательств; привлечение третьей стороны для увеличения эффективности осуществляемой сделки; обеспечение сохранности имущества у лиц, которые не обладают на него правом собственности; значительное уменьшение рисков мошенничества. 
Исходя из содержания и основных целей, договор условного депонирования должен содержать следующие пункты:

1) общая цена основного контракта и его основные положения;

2) условия исполнения договорных обязательств;

3) список документов, которые должны подписать и передать эскроу-агенту обе стороны;

4) дата исполнения основного обязательства;

5) порядок выплаты вознаграждения эскроу-агенту и т. д.

Договор счета эскроу - простая и практичная конструкция, которая позволит сторонам договора избежать недобросовестных действий и обмана в процессе передачи недвижимого имущества или исполнения других договорных обязательств.

\section{Возникновение и развитие эскроу-соглашений}

Впервые термин «эскроу» (англ. escrow) появился в США. В Америке институт ипотеки получил наибольшее развитие, поэтому появилась необходимость в выработке законодательного механизма защиты такого вида сделок. На данный момент здесь практически каждая сделка, связанная с продажей недвижимости, проходит через счета эскроу. Так, например, счета эскроу очень часто используют при заключении сделок продавцы, желающие продать имущество, которое находится за рубежом, так как услуги эскроу-агента не требуют личного присутствия сторон при заключении сделки, а это, в свою очередь, не только экономит время и деньги, но и способствует обеспечению безопасности имущества, являющегося предметом сделки. Данный механизм работает следующим образом: продавец и покупатель заключают между собой контракт, содержащий необходимые условия, при исполнении которых эскроуагент (кредитные организации (банки), юридические компании и др.) передает деньги продавцу. Покупатель переводит деньги на счет эскроу, а эскроу-агент, в свою очередь, переводит деньги продавцу сразу после передачи документов на недвижимость либо наступления определенной даты / события.
Данный вид договора в российских реалиях - явление относительно новое. Положения о договорах счета эскроу впервые появились в Гражданском кодексе Российской Федерации в 2014 г. (ст. 860.7-860.10 ГК РФ), но данная модель в России не получила такого широкого распространения, как в зарубежных странах. Гражданский кодекс ограничивался лишь появлением нового счета - счета эскроу, обладающего при этом рядом недостатков. Во-первых, роль эскроу-агента могли выполнять исключительно банки; во-вторых, депонированию подлежали только денежные средства; в-третьих, отсутствовали меры защиты от взысканий денежных средств, находящихся на счетах эскроу. В связи с данными особенностями счета эскроу в то время не приобрели должного распространения в России, а в 2017 г. банки вообще перестали оказывать подобные услуги.

Благодаря поправкам в ГК РФ, вступившим в силу 1 июня 2018 г., появилась новая глава «Условное депонирование (эскроу)» (ст. 926.1-926.8 ГК РФ), которая предоставила участникам сделок с недвижимостью более проработанный механизм. Данными поправками был впервые введен новый вид договора - договор эскроу, или договор условного депонирования. Эскроу-агентами теперь могут стать не только банки, но и нотариусы, физические и юридические лица, а также юридические компании. Преимущество привлечения юридической компании в качестве эскроу-агента состоит в том, что данная компания не только осуществляет функцию эскроу-агента, но и оказывает соответствующую правовую поддержку в рамках данных отношений.

Впервые была установлена нотариальная форма такого договора (в некоторых случаях возможна простая письменная), указан конкретный срок отношений участников по эскроу (не более пяти лет), депонировать стало возможно не только безналичные денежные средства, но и другое имущество (например, ценные бумаги, документы и т. д.). Также впервые были введены меры по защите депонируемого имущества, а именно запрет на взыскание депонируемого имущества по долгам депонента (покупателя), эскроу-агента либо бенефициара (продавца). 


\section{Договор счета эскроу в некоторых зарубежных странах}

Практика заключения договоров условного депонирования в зарубежных странах довольно распространена. В таких странах, как США, Швейцария, Великобритания, Германия, Китай и Япония, практически ни одна сделка (это может быть и поглощение компаний, и лицензирование отношений, и покупка или продажа недвижимости и т. д.) не проходит без заключения договора счета эскроу [2]. Популярность данного механизма обусловлена его удобством и практичностью, что позволяет надлежащим образом обеспечивать исполнение обязательств по договору.

В зарубежных странах договор счета эскроу является достаточно распространенным и универсальным, что позволяет сторонам повысить собственную уверенность в получении ими желаемого результата. Даже если сделка, заключенная посредством данного договора, по каким-либо причинам не состоится, депонент всегда сможет вернуть часть денежных средств, которые он намеревался передать бенефициару, но не передал, поскольку тот в силу различных обстоятельств не смог исполнить договорные обязательства надлежащим образом.

В случае если стороны пришли к обоюдному согласию заключить договор условного депонирования, то в первую очередь они должны обратиться в компанию эскроу (escrowcompany), в которой квалифицированные специалисты проведут ряд необходимых проверок недвижимости, а также сформируют пакет документов, позволяющий передать право собственности одной стороны другой. Подобные действия позволят сторонам избавиться от возможного мошенничества или махинаций, которые нередко возникают при куплепродаже недвижимости. Первичное сопровождение сделки компанией эскроу (оформление необходимой документации) обычно занимает от 15 до 45 дней и стоит от 7 тыс. до 9 тыс. долларов США.

Так, ст. 1057 Гражданского кодекса Калифорнии гласит, что имущество, подлежащее передаче по договору, может быть передано третьему лицу, которое передает его во исполнение договора только при наступлении определенных условий. В данном кодексе под понятием «эскроу» как раз и подразумевается владение имуществом третьим лицом под определенные условия.

В Англии счета эскроу чаще всего применяются при заключении сделок на передачу в собственность предметов частной собственности. Эскроу-агент удерживает на своем счете часть денежных средств депонента, а затем передает бенефициару при завершении операции. Также наиболее часто данные счета используются при покупке подержанных автомобилей (деньги покупателя переводятся агентом продавцу по истечении оговоренного гарантийного периода), при передаче арендной платы за недвижимость (арендодатель получает деньги только после того, как арендатор съехал с жилплощади) или же при оплате строительных работ (деньги переводятся исполнителю ремонтных работ только после проведения части работ или же всей работы в целом).

Также в зарубежных странах пользуется популярностью такой вид договора, как интернет-эскроу. Данный вид договора появился вместе с развитием торговли по Интернету и гарантировал пользователям сохранность денежных средств при заключении определенных сделок. Интернет-эскроу построен на том же принципе, что и обычный договор условного депонирования: одна из сторон передает определенную сумму независимой третьей стороне, обладающей соответствующей лицензией на осуществление данного вида деятельности. В случае, если обе стороны подтвердили исполнение всех договорных обязательств, эскроу-агент передает деньги продавцу (бенефициару). Если же между сторонами возникли какие-либо разногласия, они переходят к процессу разрешения спора. На данный момент в сети Интернет существует большое количество удобных сервисов, позволяющих воспользоваться услугами эскроу-агента быстро и дешево.

\section{Отличия договора эскроу}

от других форм расчетов и способов обеспечения исполнения обязательств

Немаловажным остается вопрос сходства договора эскроу с другими механизма- 
ми защиты сторон при заключении тех или иных сделок.

Основные отличия договора счета эскроу от других форм расчетов обусловлены его следующими особенностями:

1) как правило, депонент и бенефициар не имеют права каким-либо образом использовать или распоряжаться денежными средствами, хранящимися на счете эскроу. Банк (или иной эскроу-агент) переводит бенефициару денежные средства в установленный срок (если срок в договоре не указан - максимум в течение 10 дней) только в случае возникновения определенных условий или наступления событий, оговоренных в договоре. Поэтому можно прийти к выводу о том, что на договор эскроу не распространяется правило запрета на ограничение прав клиента на использование денежных средств, находящихся на счете;

2) перевод депонентом дополнительных денежных средств на счет эскроу помимо суммы, указанной в договоре, запрещается;

3) и депонент, и бенефициар имеют право требовать от эскроу-агента сведения, составляющие банковскую тайну;

4) банк закрывает счет эскроу по истечении срока действия договора или по иным основаниям, предусмотренным договором;

5) договор условного депонирования не может быть расторгнут в одностороннем порядке.

Так, например, многие ученые-правоведы придерживаются мнения о том, что договор условного депонирования и исполнение обязательств в депозит нотариуса имеют много общего. Однако между ними существуют и кардинальные различия, а именно:

1. Внесение долга в депозит нотариуса или суда имеет место быть только в том случае, если обязательство перед кредитором по каким-либо основаниям не может быть выполнено. Оснований может быть достаточно много. Это, например, отсутствие самого кредитора, его недееспособность, уклонение кредитора от принятия обязательств и т. д. Поэтому можно сделать вывод о том, что в случае исполнения обязательств перед нотариусом речь всегда идет о неопределенности лица (кредитора) либо о его отсутствии. Что касается договора эскроу, то тут лицо, обязываю- щееся принять исполнение, всегда определено - это бенефициар.

2. В депозит нотариуса, как правило, вносится имущество во исполнение тех обязательств, по которым срок уже наступил. В договоре эскроу исполнение обязательств перенесено на определенный срок либо при наличии определенных условий, событий.

Существует также мнение о значительном сходстве договора эскроу и договора хранения. Отличия между данными гражданскоправовыми договорами заключается в следующем: во-первых, лицо, имеющее определенное имущество на хранении (хранитель), не обладает полномочиями по проверке соблюдения условий договора или же выбору лица, которое, по его мнению, является надлежащим получателем исполнения; во-вторых, хранитель обязан вернуть поклажедателю ту самую вещь, которую он получил от него на хранение.

Нередко договор условного депонирования сравнивают и с арендой банковской ячейки. Самым серьезным различием здесь является тот факт, что в рамках договора эскроу существует возможность пользования передаваемым имуществом в период депонирования. Так, в зарубежных странах помещение денежных средств на банковском счете с начислением процентов на депонируемую сумму является вполне обычной практикой. В случае же с банковской ячейкой таких возможностей ни у одной из сторон нет.

Наиболее часто в правовой литературе встречается сравнение договора условного депонирования с аккредитивом. Рассмотрим различия между данными формами расчетов.

Как известно, существует два вида аккредитивов: покрытый (депонированный) и непокрытый (гарантированный) аккредитив. При сравнении договора эскроу с покрытым аккредитивом становится очевидным тот факт, что в российском законодательстве механизм условного депонирования наиболее близок именно к этой форме расчета. Различие между ними выявляется прежде всего в том, что, в отличие от аккредитива, перечисление денежных средств кредитору (бенефициару) в рамках договора эскроу осуществляется только в том случае, если им были выполнены все договорные обязательства, а не при предъявлении документов. Поэтому до- 
говор условного депонирования выигрывает при заключении сложных сделок, где платеж можно получить только при наступлении определенной даты или события, а не при формальном предоставлении документов.

Непокрытый аккредитив, напротив, отличается от договора эскроу кардинальным образом. Непокрытый аккредитив выполняет функцию кредитования, а по договору эскроу передача имущества осуществляется обязанной стороне.

Говоря о различиях между аккредитивом и договором эскроу, стоит также упомянуть тот факт, что аккредитив реализуется только при участии банка (возможно участие и нескольких банков), а в рамках договора условного депонирования стороны обладают большей свободой выбора, так как в соответствии с действующим российским законодательством в качестве эскроу-агента могут выступать не только банки, но и юридические компании и другие организации, обладающие соответствующими полномочиями.

\section{Выводы}

В современных условиях развития бизнеса договор счета эскроу пользуется достаточной популярностью, которая с каждым годом только возрастает. С помощью договора условного депонирования стало возможным противодействие таким насущным проблемам, как легализация доходов, полученных противоправными методами, осуществление мошеннических действий в рамках гражданского оборота и др. Удобство в использовании и относительная дешевизна услуг эскроуагентов увеличивают привлекательность данного гражданско-правового инструмента, при этом торговля в сети Интернет в зарубежных странах практически не обходится без помощи эскроу-компаний.

Счет эскроу - это специальный счет, который открывается в банке, где резервируются средства участника долевого строительства на время строительства дома и передаются застройщику только после того, как им будут выполнены все обязательства, предусмотренные договором. Если же последний не сможет их исполнить, то банк вернет денежные средства участнику.
Суть данных расчетов состоит в том, что участник договора долевого строительства вносит денежную сумму не напрямую на счет застройщика, а на счет банка. Эта система подвергается критике, так как договор долевого участия в строительстве предполагает, что застройщик привлекает в проект денежные средства граждан для того, чтобы приобретать строительные материалы, оплачивать услуги подрядных организаций и большое количество других расходов. Возникает вопрос: откуда взять средства на строительство данного объекта? Поэтому банк, в котором обслуживается участник долевого строительства, обеспечивает денежными средствами застройщика объекта проектным кредитованием.

В настоящее время проектное кредитование могут использовать достаточно крупные застройщики, что приведет к уходу неконкурентоспособных организаций, осуществляющих строительство. Но также это повлечет за собой рост стоимости жилья, так как застройщик будет вкладывать собственные средства в дополнительные расходы.

Договор счета эскроу в этой сфере, безусловно, выгоден для банков, так как банки выдают ипотечные кредиты участникам строительства, кредиты застройщикам, при этом безвозмездно пользуются денежными средствами в своих целях.

В рамках государственной финансовой программы «Обеспечение доступным и комфортным жильем и коммунальными услугами граждан РФ и формирование комфортной сельской среды», предусмотренной на 20182025 гг, объемы строительства жилья возрастают с каждым годом, и к 2025 г. планируется увеличение до 120 млн квадратных метров [3].

Использование счетов эскроу приведет к положительным изменениям, потому что за счет накопления огромных денежных средств дольщиков на счетах банки будут иметь возможность регулировать процентные ставки для населения - в первую очередь для ипотеки и проектного финансирования.

Несмотря на то что в России договор эскроу начал использоваться при заключении различных сделок всего несколько лет назад, многие ученые-правоведы приходят к едино- 
гласному мнению о том, что перспективы развития у договора условного депонирования все-таки есть [1]. Прогнозы говорят о том, что в ближайшем будущем российский законодатель значительно расширит сферу применения данного договора. Увеличения популярности услуг эскроу-агентов можно добиться с помощью расширения их субъектного состава, а также посредством снятия ограничений в выборе объектов условного депонирования (законодательно позволить депонировать не только денежные средства, но и любое другое имущество по усмотрению депонента).

Необходима дальнейшая глубокая исследовательская деятельность, которая позволит наиболее полно и точно сформулировать понятие договора условного депонирования, определить место данного вида гражданско-правовых договоров в системе гражданского права Российской Федерации, а также выявить особенности заключения сделок с привлечением эскроу-агентов как в России, так и за рубежом.

\section{СПИСОК ЛИТЕРАТУРЫ}

1. Белокопытова, Н. Ю. Договор эскроу как новый способ обеспечения исполнения обязательств / Н. Ю. Белокопытова, В. В. Колесникова // Вестник Омской юридической академии. - 2019. T. 16, № 1. - С. 23-27.

2. Василевская, Л. Ю. Договор счета эскроу: проблемы правовой квалификации / Л. Ю. Василевская // Электронное приложение к «Российскому юридическому журналу». - 2016. - № 2. - Электрон. текстовые дан. - Режим доступа: http:// electronic.ruzh.org/?q=ru/system/files/vasilevskaya. pdf (дата обращения: 25.12.2019). - Загл. с экрана.

3. Государственная программа Российской Федерации «Обеспечение доступным и комфортным жильем и коммунальными услугами граждан Российской Федерации». - Электрон. текстовые дан. - Режим доступа: https://strategy24.ru/rf/ citybuilding-and-jkh/programs/gosudarstvennayaprogramma-rossiyskoy-federatsii-obespecheniyedostupnym-i-komfortnym-zhil-yem-i-kommunal-nymiuslugami-grazhdan-rossiyskoy-federatsii. - Загл. с экрана.

4. «Комсомольская правда»: Глава Минстроя Владимир Якушев: Число обманутых дольщиков снизим до нуля // Минстрой России. - Электрон. текстовые дан. - Режим доступа: https://www. minstroyrf.ru/press/komsomolskaya-pravda-glavaminstroya-vladimir-yakushev-chislo-obmanutykhdolshchikov-snizim-do-nulya/?sphrase_id $=868250$ (дата обращения: 25.12.2019). - Загл. с экрана.

5. Мутко: 14 банков рассматривают около 800 заявок по долевому строительству. - Электрон. текстовые дан. - Режим доступа: https:/realty.ria.ru/ 20190422/1552938720.html (дата обращения: 25.12.2019). - Загл. с экрана.

6. Федеральный закон от 30.12.2004 № 214-Ф3 (ред. от 27.06.2019) «Об участии в долевом строительстве многоквартирных домов и иных объектов недвижимости и о внесении изменений в некоторые законодательные акты Российской Федерации» // Собрание законодательства РФ. - 2005. - 3 янв. (№ 1, ч. 1). - Ст. 40 ; 2019. - 1 июля (№ 26). - Ст. 3317.

\section{REFERENCES}

1. Belokopytova N.Yu., Kolesnikova V.V. Dogovor eskrou kak novyy sposob obespecheniya ispolneniya obyazatelstv [Escrow Agreement As a New Way to Ensure Fulfillment of Obligations]. Vestnik Omskoy yuridicheskoy akademii [Bulletin of the Omsk Law Academy], 2019, vol. 16, no. 1, pp. 23-27.

2. Vasilevskaya L.Yu. Dogovor scheta eskrou: problemy pravovoy kvalifikatsii [Escrow Account Agreement: Problems of Legal Qualification]. Elektronnoe prilozhenie $k$ «Rossiyskomu yuridicheskomu zhurnalu» [Electronic Appendix to the Russian Legal Journal], 2016, no. 2. URL: http:// electronic.ruzh.org/?q=ru/system/files/vasilevskaya. pdf (accessed 25 December 2019).

3. Gosudarstvennaya programma Rossiyskoy Federatsii «Obespechenie dostupnym i komfortnym zhilyem i kommunalnymi uslugami grazhdan Rossiyskoy Federatsii» [State Program of the Russian Federation "Providing Affordable and Comfortable Housing and Utilities to Citizens of the Russian Federation"]. URL: https://strategy24.ru/rf/ citybuilding-and-jkh/programs/gosudarstvennayaprogramma-rossiyskoy-federatsii-obespecheniyedostupnym-i-komfortnym-zhil-yem-i-kommunal-nymiuslugami-grazhdan-rossiyskoy-federatsii.

4. «Komsomolskaya pravda»: Glava Minstroya Vladimir Yakushev: Chislo obmanutykh dolshchikov snizim do nulia ["Komsomolskaya Pravda": Head of the Ministry of Construction Vladimir Yakushev: The Number of Deceived Shareholders Will Be Reduced to Zero]. Minstroy Rossii [Ministry of Construction of Russia]. URL: https://www.minstroyrf.ru/press/komsomolskayapravda-glava-minstroya-vladimir-yakushev-chisloobmanutykh-dolshchikov-snizim-do-nulya/ ?sphrase id=868250 (accessed 25 December 2019). 
5. Mutko: 14 bankov rassmatrivayut okolo 800 zayavok po dolevomu stroitelstvu [Mutko: 14 Banks Are Considering About 800 Applications for Shared-Equity Construction]. URL: https://realty.ria.ru/ 20190422/1552938720.html (accessed 25 December 2019).

6. Federalnyy zakon ot 30.12.2004 № 214-FZ (red. ot 27.06.2019) «Ob uchastii v dolevom stroitelstve mnogokvartirnykh domov i inykh obyektov nedvizhimosti i o vnesenii izmeneniy v nekotorye zakonodatelnye akty Rossiyskoy Federatsii» [Federal Law of December 30, 2004 no. 214-FZ (ed. of 27.06.2019) "On Participation in Shared Construction of Apartment Buildings and Other Real Estate Objects and on Amendments to Certain Legislative Acts of the Russian Federation"]. Sobranie zakonodatelstva $R F$ [Collection of Legislation of the Russian Federation], 2005, 3 Jan. (no. 1, part 1), art. 40; 2019, 1 Jule (no. 26), art. 3317.

\section{Information About the Author}

Natalia V. Kvitsinia, Candidate of Sciences (Jurisprudence), Associate Professor, Department of Civil and Private International Law, Base Department of the Southern Scientific Centre of the Russian Academy of Sciences, Volgograd State University, Prosp. Universitetsky, 100, 400062 Volgograd, Russian Federation, maksim20777@yandex.ru, https://orcid.org/0000-0002-6538-9796

\section{Информация об авторе}

Наталья Вячеславовна Квициния, кандидат юридических наук, доцент кафедры гражданского и международного частного права (базовая кафедра ЮНЦ РАН), Волгоградский государственный университет, просп. Университетский, 100, 400062 г. Волгоград, Российская Федерация, maksim20777@yandex.ru, https://orcid.org/0000-0002-6538-9796 